\title{
Efektivitas Straegi Bauran Promosi Oleh_Oleh Makanan Khas Riau (Studi Kasus Pada Wisatawan Di Kota Pekanbaru)
}

\author{
ZULIA KHAIRANI ${ }^{1}$ NURHAYANI LUBIS ${ }^{2}$ \\ ${ }^{1}$ Universitas Lancang Kuning, Pekanbaru 28265, Indonesia \\ Telp:+628126736104, Fax: +6276153108 \\ E_mail: zuliakhairani@unilak.ac.id; nurhayanilubis@unilak.ac.id
}

\begin{abstract}
For the sake of promoting and inviting tourist to tourist resort, there are some factors that should be considered as value added. One of them is spesific foods as part of local culture characteristic. Promotional activities is an important role to introduce and cultivate the interest of tourists in a souvenir typical regional foods. The aims of the study were to analyze the level of promotion mix consists of advertising, sales promotion, direct marketing, personal selling, and public relations, and to find out the level of consumer buying interest, and finally investigate the influence of promotional mix on consumer purchase intention of the tourists. The sample in this study were 100 tourists. The method used were combination of quantitative and qualitative analysis. The data was purposively taken using quantitative analysis. Quantitative analysis, that is, descriptive analysis was performed with the interpretation of the data obtained in the study and the results of data processing that had been carried out by providing information and explanations. The results showed that advertising, personal selling, and public relations are in good criteria. While sales promotion and direct marketing are in medium criteria.
\end{abstract}

Keywords: advertising, sales promotion, direct marketing, personal selling, and public relations, promotions mix

Pemasaran pariwisata daerah merupakan bagian dari pemasaran sektor jasa. Pengembangan industri pariwisata sangat dimungkinkan mengingat begitu kayanya Indonesia dengan banyaknya ragam pesona, mulai dari alam, sejarah, serta budaya. Semua daya pesona itu tentu tidak dapat begitu saja memberi nilai tambah bila kemudian tidak diiringi dengan usaha menggugah minat pasar untuk mengunjungi serta menikmati berbagai objek wisata serta hasil industri ekonomi kreatif yang ada.

Salah satu hasil industri ekonomi kreatif yang mendukung dalam pengembangan pariwisata daerah adalah makanan khas daerah yang merupakan bagian dari budaya daerah setempat. Penelitian Boyne dkk pada tahun 2002 dalam Aruman (2014) menunjukkan bahwa wisatawan menghabiskan hampir $40 \%$ dari anggaran mereka pada makanan saat bepergian, pernyataan ini juga didukung oleh penelitian Graziani tahun 2003 yang mengatakan bahwa $50 \%$ dari pendapatan restoran dihasilkan oleh wisatawan (http://mix.co.id/, diakses tanggal 4 April 2016).

Riau merupakan salah satu provinsi dari 35 provinsi yang ada di Indonesia, memiliki potensi pariwisata yang menarik seperti kebanyakan daerah lainnya di Indonesia. Berdasarkan penilaian ajang Gebyar Wisata Nusantara yang diadakan di Jakarta tahun 2015, Riau ditempatkan sebagai provinsi yang memiliki potensi pariwisata dan ekonomi kreatif kedua terbaik sesudah Aceh, hanya saja masih kurang dalam hal pengemasan dan pemasarannya (www.riaupos.co, diakses 22 April 2016). Selain itu provinsi Riau juga memiliki 250 jenis makanan khas daerah yang berpotensi untuk diperkenalkan dan dipromosikan sebagai salah satu daya tarik wisatawan berkunjung ke Riau. Organisasi Ikaboga Riau telah melakukan pendataan terhadap makanan tradisional, terdapat 250 jenis makanan tradisional dan yakin akan terus bertambah jumlah makanan tradisional di 
Riau yang harus dilestarikan (www.riau.go.id, diakses 22 April 2016)

Riau berpotensi besar dalam wisata makanan (food tourism) karena memiliki kekayaan etnis dan budaya, serta memiliki kuliner khas dan beragam. Berkembangnya wisata makanan juga merupakan peluang masyarakat daerah Riau untuk mengembangkan makanan dan minuman khas Riau agar bisa dikenal lebih luas lagi sekaligus meningkatkan daya tarik wisatawan lokal dan mancanegara. Makanan khas daerah Riau juga dapat menjadi salah satu oleh-oleh khas daerah yang dibawa wisatawan ke daerah asalnya. Oleh karena itu kemampuan mengolah, menyajikan, menampilkan, dan mempromosikan makanan khas daerah dengan baik sangat menentukan penghasilan yang didapatkan dalam sektor pariwisata. Adapun jenis oleh-oleh makanan khas Riau yang cukup dikenal dan banyak diminati antara lain :

Tabel 1.1. Beberapa Oleh-Oleh Makanan Khas Riau

\begin{tabular}{|l|l|l|l|}
\hline No. & Nama Makanan & Harga & Daeral Asal \\
\hline 1. & Bolu Cermai & Rp 18.000 & Pekanbaru \\
\hline 2. & Lempuk Durian Kotak & $\operatorname{Rp~45.000}$ & Bengkalis \\
\hline 3. & $\begin{array}{l}\text { Lempuk Durian } \\
\text { Panjang }\end{array}$ & $\operatorname{Rp~30.000}$ & Bengkalis \\
\hline 4. & Kue Bangkit Riau & $\operatorname{Rp~25.000}$ & Pekanbaru \\
\hline 5. & Keripik Nenas & $\operatorname{Rp~25.000~}$ & Kampar \\
\hline 6. & Bolu Kemojo & $\operatorname{Rp~20.000~}$ & Pekanbaru \\
\hline 7. & Kacang Pukul & $\operatorname{Rp~25.000~}$ & Bagan Siapi-api \\
\hline 8. & Keripik Nangka & $\operatorname{Rp~25.000~}$ & Kampar \\
\hline 9. & Peyek Ikan Selais & $\operatorname{Rp~32.000~}$ & Pekanbaru \\
\hline
\end{tabular}

Sumber : www.oleholehriau.com

Untuk menumbuhkan minat wisatawan mencoba dan membeli makanan khas daerah, diperlukan upaya berbagai strategi pemasaran yang efektif salah satunya dengan kegiatan promosi. Menurut Kotler dan Armstrong (2008 : 116), bauran promosi (promotion mix) juga disebut bauran komunikasi pemasaran (marketing communication mix) perusahaan merupakan paduan spesifik iklan, promosi penjualan, sarana pemasaran langsung, penjualan personal, dan hubungan masyarakat yang digunakan perusahaan untuk mengkomunikasikan nilai pelanggan secara persuasif dan membangun hubungan pelanggan. Bentuk-bentuk kegiatan promosi dapat melalui periklanan (advertising), penjualan langsung (personal selling), promosi penjualan (sales promotion), hubungan masyarakat (public relation), dan pemasaran langsung (direct marketing). Kotler dan Armstrong (2008 : 150) mendefinisikan periklanan (advertising) dalam hal ini merupakan semua bentuk presentasi nonpribadi dan promosi ide, barang, atau jasa yang dibayar oleh sponsor tertentu.

Menurut Kotler dan Armstrong (2008 : 157) adapun suatu iklan memiliki karakteristik sebagai berikut: 1 . Penemuan informasi tentang produk / perusahaan dari berbagai media mudah, 2 . Design media yang digunakan menarik, 3.Informasi yang disampaikan dalam berbagai media jelas, 4. Pesan yang terkandung dalam berbagai media dapat dipercaya.

Kotler dan Armstrong (2008: 204) mendefinisikan promosi penjualan (sales promotion) terdiri dari insentif jangka pendek untuk mendorong pembelian atau penjualan sebuah produk atau jasa. Karakteristik dari sales promotion menurut Kotler dan Armstrong (2008 : 204) yaitu: 1. Besar / ukuran insentif yang ditawarkan menarik, 2.Insentif yang ditawarkan bervariasi, 3.Syarat untuk mendapatkan insentif yang ditawarkan jelas, dan 4.Waktu pelaksanaan insentif yang dilakukan tepat.

Menurut Kotler dan Armstrong (2008: 223), pemasaran langsung (direct marketing) terdiri dari hubungan langsung dengan konsumen individual yang ditargetkan secara seksama untuk meraih respons segera dan membangun hubungan pelanggan yang langgeng. Karakteristik

p.ISSN: $2407-800 X \quad$ e.ISSN: $2541-4356$ 
dari direct marketing menurut Kotler dan Armstrong (2008 : 222) yaitu :1.Interaksi melalui pemasaran langsung yang interaktif, 2. Interaksi dari perusahaan yang interaktif

Menurut Kotler dan Armstrong (2008 : 182), penjualan personal (personal selling) adalah presentasi pribadi oleh wiraniaga perusahaan dengan tujuan melakukan penjualan dan membangun hubungan dengan pelanggan. Kotler dan Armstrong (2008 : 200) mendeskripsikan karakteristik dari personal selling adalah: 1.Penampilan wiraniaga baik, 2.Wiraniaga menguasai informasi perusahaan, 3.Kemampuan wiraniaga dalam menjelaskan produk bagi pelanggan memuaskan, 4.Wiraniaga dapat mengidentifikasi konsumen baru atau konsumen lama dengan baik.

Menurut Kotler dan Armstrong (2008 : 168), hubungan masyarakat (public relations) membangun hubungan baik dengan berbagai masyarakat perusahaan dengan memperoleh publisitas yang diinginkan, membangun citra perusahaan yang baik, dan menangani atau menghadapi rumor, cerita, dan kejadian tak menyenangkan. Adapun kriteria public relations menurut Kotler dan Armstrong (2008 : 171) dapat dibedakan menjadi tiga hal yaitu: 1. Berita yang tersebar mengenai perusahaan baik, 2.Identitas perusahaan yang unik, berbeda dari yang lainnya, 3. Kegiatan pelayanan masyarakat.

Bauran promosi ini digunakan untuk mengkomunikasikan kegiatan perusahaan kepada konsumen. Komunikasi yang efektif akan mengubah tingkah laku konsumen dan akan memperkuat tingkah laku yang telah diubah sebelumnya.. Menurut Tjiptono (2008: 222), bauran promosi terdiri dari atas 5 perangkat utama yakni: Advertising, merupakan semua penyajian non personal,promosi ide-ide, promosi produk atau jasa yang dilakukan sponsor tertentu yang dibayar, Sales Promotion, Berupa insentif jangka pendek untuk mendorong keinginan mencoba atau membeli suatu produk atau jasa. Personal Selling,
Interaksi langsung dengan calon pembeli atau lebih untuk melakukan presentasi, menjawab langsung dan menerima pesanan. Hubungan masyarakat, Berbagai program untuk mempromosikan dan atau melindungi citra perusahaan atau produk individualnya. Direct Marketing, Penggunaan surat, telepon, faksimil, email dan alat penghubung non-personal lain untuk berkomunikasi secara dengan atau mendapatkan tanggapan langsung dari pelanggan tertentu dan calon pelanggan

Pengaruh promosi penjualan biasanya berumur pendek, dan sering tidak seefektif iklan atau penjualan personal dalam membangun preferensi merek jangka panjang dan hubungan pelanggan. Sedangkan hubungan masyarakat sangat terpercaya (berita, fitur, program sponsor, dan acara) tampak lebih nyata dan terpercaya bagi pemirsa daripada iklan. Kampanye hubungan masyarakat yang dikemas baik dan digunakan bersama elemen bauran promosi lainnya bisa sangat efektif dan ekonomis. Adapun pemasaran langsung bersifat nonpublic, pesan biasanya diarahkan kepada orang tertentu. Pemasaran langsung bersifat segera dan disesuaikan. Pesan dapat dipersiapkan dengan cepat dan dapat dibentuk agar sesuai dengan konsumen tertentu

\section{METODE}

Jenis penelitian yang digunakan adalah penelitian survey. Populasi dalam penelitian ini adalah wisatawan yang berkunjung di kota Pekanbaru pada bulan Juni 2017 - Agustus 2017. Di Indonesia, musim libur terjadi dibulan-bulan tersebut diantaranya libur sekolah, libur bulan puasa dan Idul Fitri. Metode pengambilan sampel yang digunakan adalah purposive sampling. Purposive sampling melibatkan penggunaan pengetahuan peneliti dari populasi untuk tujuan penelitian.

Metode pengumpulan data yang digunakan dalam penelitian ini adalah metode survei yang menggunakan daftar

p.ISSN: $2407-800 X \quad$ e.ISSN: 2541-4356 
pertanyaan (kuesioner). Lokasi penyebaran kuesioner direncanakan di ruang tunggu keberangkatan Bandara Sultan Syarif Kasim II Pekanbaru. Lokasi ini dipilih agar suasana pengambilan data lebih tenang dan data yang diambil diharapkan lebih tepat dan akurat. Teknik analisis data yang digunakan adalah teknik deskriptif.

\section{HASIL}

Berdasarkan hasil pengumpulan data kuesioner didapatkan profil responden Berdasarkan profil responden diatas, pada kategori usia terbanyak pada usia responden 17-29 tahun. Dari kategori jenis kelamin terbanyak adalah perempuan, tingkat pendidikan responden terbanyak adalah tamatan SMA dan sarjana. Jenis oleh-oleh makanan khas Riau yang paling populer bagi responden adalah lempuk durian dan bolu kemojo. Berikut adalah hasil rangkuman atas seluruh penjelasan deskriptif dari indikatorindikator varibel di penelitian ini:

Tabel 3. Penjelasan deskiptif setiap indikator variabel

\begin{tabular}{|c|c|c|c|}
\hline No. & Pernyataan & Skor & $\begin{array}{l}\text { Rata- } \\
\text { Rata }\end{array}$ \\
\hline \multicolumn{4}{|c|}{ A. $\quad$ Advertising } \\
\hline 1. & $\begin{array}{l}\text { Penemuan informasi tentang produk/perusahaan } \\
\text { dari berbagai media mudah }\end{array}$ & 325 & 3,25 \\
\hline 2. & Design media yang digunakan menarik & 318 & 3,18 \\
\hline 3. & $\begin{array}{l}\text { Informasi yang disampaikan dalam berbagai } \\
\text { media jelas }\end{array}$ & 311 & 3,11 \\
\hline 4. & $\begin{array}{l}\text { Pesan yang terkandung dalam berbagai media } \\
\text { dapat dipercaya }\end{array}$ & 317 & 3,17 \\
\hline \multicolumn{4}{|c|}{ B. Sales Promotion } \\
\hline 1. & Besar/ ukuran insentif yang ditawarka & 277 & 2,77 \\
\hline 2. & Insentif yang ditawarkan bervariasi & 266 & 2,66 \\
\hline 3. & $\begin{array}{l}\text { Syarat untuk mendapatkan insentif yang } \\
\text { ditawarkan jelas }\end{array}$ & 271 & 2,71 \\
\hline 4. & $\begin{array}{l}\text { Waktu pelaksanaan insentif yang dilakukan } \\
\text { tepat }\end{array}$ & 306 & 3,06 \\
\hline \multicolumn{4}{|c|}{ C. Direct Marketing } \\
\hline 1. & $\begin{array}{l}\text { Interaksi melalui pemasaran langsung yang } \\
\text { interaktif }\end{array}$ & 284 & 2,84 \\
\hline 2. & Interaksi dari perusahaan yang interaktif & 273 & 2,73 \\
\hline \multicolumn{4}{|c|}{ D. Personal Selling } \\
\hline 11. & Penampilan wiraniaga yang baik & 325 & 3,25 \\
\hline 12. & Wiraniaga menguasai informasi perusahaan & 336 & 3,36 \\
\hline 13 & $\begin{array}{l}\text { Kemampuan wiraniaga dalam menjelaskan } \\
\text { produk bagi pelanggan memuaskan }\end{array}$ & 323 & 3,23 \\
\hline 14. & $\begin{array}{l}\text { Wiraniaga dapat mengidentifikasi konsumen } \\
\text { baru atau konsumen lama dengan baik. }\end{array}$ & 315 & 3,15 \\
\hline \multicolumn{4}{|c|}{ E. Public Relation } \\
\hline 15. & Berita yang tersebar mengenai perusahaan baik & 324 & 3.24 \\
\hline 16. & $\begin{array}{l}\text { Identitas produk yang unik, berbeda dari yang } \\
\text { lainnya. }\end{array}$ & 303 & 3.03 \\
\hline 17. & Kegiatan pelayanan masyarakat & 294 & 2.94 \\
\hline
\end{tabular}

Sumber : Data Olahan Kuesioner 2017

Berdasarkan data diatas terlihat bahwa tanggapan konsumen pada semua indikator variabel strategi bauran promosi oleh-oleh makanan khas Riau pada kriteria cukup baik dan baik.

\section{PEMBAHASAN}

Dalam penelitian ini ditemukan bahwa tanggapan wisatawan pada advertising pada kriteria baik. Hal ini disebabkan karena wisatawan dapat melihat dan menemukan berbagai iklan oleh-oleh makanan khas Riau melalui berbagai media saat mereka mengunjungi kota Pekanbaru. Usaha yang menjual oleh-oleh makanan khas Riau juga mudah ditemukan dan beberapa perusahaan roti terkenal di kota Pekanbaru juga ikut mengiklankan dan menjual produk oleh-oleh makanan khas Riau.

Pada sales promotion, skor hasil deskriptif menunjukkan tanggapan konsumen pada kriteria sedang. Beberapa perusahaan sudah menawarkan beberapa bentuk insentif atau promosi bagi konsumen, seperti sampel produk gratis, hadiah produk gratis dengan batas minimal pembelian, dan bentuk promosi lainnya. Hanya saja bentuk-bentuk insentif yang lebih bervariasi biasanya ditawarkan oleh perusahaan roti dan kue yang besar di kota Pekanbaru. sedangkan untuk UMKM yang menjual oleh-oleh makanan khas Riau masih minim dalam menawarkan bentukbentuk insentif yang bervariasi bagi konsumen.

Tanggapan konsumen pada direct marketing pada kriteria sedang. Interaksi antara konsumen dan usaha oleh-oleh makanan khas Riau selama ini terlihat masih minim, tanpa adanya kegiatan interaksi dengan konsumen yang berkelanjutan. Beberapa perusahaan besar yang menjual oleh-oleh makanan khas Riau mungkin sudah lebih baik dalam melakukan interaksi dengan konsumennya melalui kegiatan pemasaran yang mereka lakukan. Akan tetapi oleh-oleh makanan khas Riau kebanyakan dijual oleh UMKM yang masih kurang dalam kegiatan pemasarannya. Dari tabel 5.2 juga terlihat bahwa skor personal selling pada kriteria baik. Hal ini menunjukkan bahwa kemampuan wiraniaga dalam menjual sudah baik dan mampu

p.ISSN: $2407-800 X \quad$ e.ISSN: $2541-4356$ 
menarik minta konsumen untuk membeli.

Tanggapan konsumen pada public relation terlihat pada kriteria baik. Berarti selama ini konsumen rata-rata memiliki persepsi yang positif pada usaha dan produk oleh-oleh makanan khas Riau yang dijual. responden juga menilai bahwa oleh-oleh makanan khas Riau unik dan memiliki ciri khas dari produk makanan lain. Selanjutnya tanggapan konsumen pada minat beli pada kriteria baik. Responden memiliki minat yang tinggi dalam membeli oleh-oleh makanan khas Riau

\section{SIMPULAN}

Dalam penelitian ini ditemukan bahwa Tingkat bauran promosi yang terdiri dari advertising, personal selling, dan public relations berada pada kriteria baik. Sedangkan sales promotion dan direct marketing berada pada kriteria sedang. Bagi Akademisi, penelitian ini dapat memberikan kontribusi terhadap pemahaman sejauh mana peran dari strategi bauran promosi terhadap minat beli pada konsumen. Bagi peneliti selanjutnya diharapkan dapat menggunakan faktor-faktor lain yang lebih khusus dari strategi bauran promosi yang dapat mempengaruhi minat beli konsumen . Penelitian ini hanya menggunakan metode survei yang memiliki kelemahan dan berpotensi bias. Penelitian selanjutnya diharapkan menggunakan metode wawancara agar dapat mengatasi kelemahan metode survei

\section{DAFTAR RUJUKAN}

Augusty Ferdinand. 2006. Metode Penelitian Manajemen. Badan Penerbit Universitas Diponegoro Semarang

Aruman, Edhy. 2014. Apa Hubungan Kuliner dan Destinasi Wisata? Diakses tanggal 4 April 2016 melalui http://mix.co.id/

Brianto, A Heri dan Oktavia Astrid. 2015. Analisis Pengaruh Bauran Promosi $\underline{\text { Kartu Prabayar Terhadap Minat Beli }}$

Jurnal Daya Saing
Nasabah Pada PT. Bank Negara Indonesia (Persero) Tbk Cabang Jatinegara. Jurnal Akuntansi, Keuangan, dan Perbankan No.3/Vol.1/ June 2015 ISSN : 23389753. Politeknik Negeri Jakarta

Daryanto, 2011. Manajemen Pemasaran : Sari Kuliah. Cetakan I, Satu Nusa, Bandung

Djatmiko, 2013. Bauran Promosi dan Minat Menjadi Nasabah : Studi Pada Nasabah PD BPR Kota Bandung. Star - Study \& Accounting Research ISSN: 16934482 Vol.X, No.3 - 2013

Fakhru Rizky,Muhammad dan Yasin, Hanifa .2014. Pengaruh Promosi dan Harga Terhadap Minat Beli Perumahan Obama PT. Nailah Adi Kurnia Sei Mencirim Medan. Jurnal Manajemen \& Bisnis Vol.14. No.2 Oktober 2014 ISSN1693-7619

Gebyar Wisata Nusantara.2015. Potensi Wisata dan Ekonomi Kreatif Riau Terbaik Nasional. Diakses tanggal 04 April 2016 melalui www.riaupos.co

Karunanithy and Sivesan. 2013. An Empirical Study on the Promotional Mix and Brand Equity: Mobile Service Providers. Industrial Engineering Letters ISSN 2224-6096 (Paper) ISSN 2225-0581 (online) Vol.3, No.3

Kotler Philip., Armstrong Garry. 2008. Prinsip-prinsip Pemasaran, Jilid 1, Erlangga, Jakarta.

Nour, almahirah and Freihat. 2014. The Impact of Promotional Mix Elements on Consumers Purchasing Decisions.

p.ISSN: $2407-800 X \quad$ e.ISSN: 2541-4356 
International Business and Management ISSN 2222-2839 (online) Vol.8 No.2, PP.143-151

Oladepo,Issac Onigbinde, et al. 2015. The Influence Of Brand Image And Promotional Mix On Consumer Buying Decision- A Study Of Beverage Consumers In Lagos State, Nigeria. British Journal of Marketing Studies Vol.3, No.4,pp.97-109, Tjiptono, Fandhy. 2008. Strategi Bisnis Pemasaran. Andi. Yogyakarta

Schiffman Leon dan Kanuk, Leslie Lazar. 2008. Consumer Behavior. PT Index. Jakarta

Summers,Jane and lorterapong, Atasit and Johnson Morgan, Melissa. 2006. Factors Influencing Consumer Intentions to Purchase Seasonally Discounted Athletic Footware in Thailand. International Bussines Trends: Contemporary Readings, The Academy Of Business Administration, pp.185-196

Sugiyono, 2014. Statistika Untuk Penelitian, Alfabeta, Bandung

Tuddin, T., \& Ling, A.W. (2012). Promotion mix: level of awareness and purchase likelihood. Retrieved April 11, 2013, from http://www.feb.unimas.my

-----. 2013. Riau miliki 250 lebih jenis makanan Tradisional.diakses tanggal 22 April 2016 melalui http:// www.riau.go.id 